\section{Physical aggression as a function of manifest anxiety*}

\author{
FRANKLIN S. DORSKY and STUART P. TAYLOR \\ Kent State University, Kent, Ohio 44244
}

The relationship between physical aggression and anxiety was investigated in 40 college males by allowing them to compete in a task involving reaction time with opponents who attempted to give them increasingly intense shocks. The high anxious Ss appeared to respond to the increasing attack in a more fearful manner than the low anxious Ss. However, the Ss who scored low on the MAS were no more aggressive than the Ss who scored high on the MAS. The results suggest that a person's underlying emotional state and overt aggressiveness can vary in a relatively independent manner.

A traditional assumption among researchers investigating the dynamics of physical aggression is that anxiety inhibits aggressive behavior (Berkowitz, 1962; Bandura \& Walters, 1959). Dengerink (1971) attempted to evaluate this hypothesis by placing high and low anxious $\mathrm{Ss}$ in a situation in which they could aggress against a provocative peer. In this study, the low anxious Ss behaved in a more aggressive manner than the high anxious Ss.

The scale used by Dengerink to preselect high and low anxious Ss was developed by Lykken (1957) to measure a person's "manifest anxiety." It requires Ss to indicate a preference for one of a pair of aversive activities or experiences. The Ss receive high ratings of anxiety if they consistently indicate a preference for onerous or tedious tasks over the embarrassing or dangerous ones.

A close examination of the 1957 version of the Lykken scale indicates that the high anxious or emotional choice on a majority of the 33 items reflects a particular form of anxiety. Examples of some of these choices include: "being seen naked by a neighbor, knocking over a glass in a restaurant, being introduced to some new people." Thus, the results of the study conducted by Dengerink might be interpreted as suggesting that aggression is inhibited by social rather than manifest or trait anxiety.

The purpose of this experiment was to explore further the presumed relationship between manifest anxiety and aggression. More specifically, an attempt was made to replicate Dengerink's results with the Taylor Manifest Anxiety Scale, the most widely used and accepted measure of trait anxiety. The MAS requires Ss to respond to statements involving their

*The research was done by the first author in partial fulfillment of the MA degree at Kent State University, under the direction of the second author. general emotional and physical condition; few of the items reflect anxiety concerning social situations.

A secondary purpose of this experiment was to investigate the effect of prior experience with pain upon the expression of physical aggression.

\section{SUBJECTS}

The Ss were male undergraduates enrolled in an introductory psychology course at Kent State University. They were selected from a pool of approximately 400 students on the basis of extreme scores on the Taylor Manifest Anxiety Scale. The final selection of Ss consisted of $20 \mathrm{Ss}$ with the highest scores on the MAS and 20 Ss with the lowest scores on the MAS. The mean anxiety scores for the high and low anxiety groups were 34.4 and 6.2 , respectively.

\section{PROCEDURE}

The $\mathbf{S}$ was seated at a task board, and a shock electrode was attached to his left wrist. After the S's "unpleasantness" threshold for shock was determined, the experience with the pain variable was manipulated. Ss in the high pain group were administered 10 shocks at the intensity they had previously judged to be definitely unpleasant. The Ss in the low pain group received 10 shocks which were $60 \%$ of the unpleasantness threshold.

Following a 1-min delay, each $\mathrm{S}$ was told that he was competing with another $S$ in an adjoining room on a task involving reaction time. At the beginning of each trial, he was instructed to select (by pressing one of five buttons) any one of five intensities of shock he wished his opponent to receive. He was informed that the shock would be administered to his opponent at the end of a trial if he was faster than his opponent and that he would receive the shock his opponent set for him if his opponent was faster. Thus, he realized that either he or his opponent would receive a shock, depending upon the outcome of the competition, and that both could select the intensity of the shock the other would receive.

Actually, there was no opponent. The frequency of wins and losses and the amount of shock received were programmed by the E.

Immediately after the task instructions were heard, the trial began. All Ss received 25 trials. These consisted of four blocks of increasing attack trials, plus an extra trial that was required to measure the $S$ 's aggressive reaction to the feedback of the 24th trial. All Ss won $50 \%$ of the trials within each of the four blocks. The first block (low attack) consisted of six trials in which the feedback settings averaged 1.5. In three of these trials, the shock setting was " 1 ," and in the other three trials, " $2 . "$ In the second block of six trials, the average shock setting was 2.5 , in the third block 3.5, and in the fourth and last block of trials (high attack) 4.5. Each trial consisted of four specific events: (1) a signal to set the degree of shock the $S$ wished his opponent to receive; (2) a ready signal, where the $S$ pressed his finger down on a telegraph key (3) the trial itself, where the $S$ released the key as quickly as possible; and (4) a feedback signal that consisted of a light that had been set for the $\mathrm{S}$ by his opponent and, if the opponent was faster, the shock as well.

In establishing the intensities of shock to be administered to the $S$, the intensity judged as "definitely unpleasant" was designated as No. 5; No. 4 was set at $90 \%$ of the maximum No. 3 at $80 \%$ of the maximum, and Nos. 2 and 1 at $70 \%$ and $60 \%$ of the maximum, respectively. RESULTS

It was assumed that low anxious Ss would behave in a more aggressive manner than high anxious Ss. However, according to an analysis of variance of mean shock settings, neither the main effect of anxiety $(F=2.14, d f=1 / 36)$ nor the Anxiety by Blocks interaction was significant. The mean shock settings for the low and high anxiety groups were, respectively, 2.81 and 2.39 .

The intensity of shock the $S$ set for his opponent increased as a function of increasing attack ( $F=47.5$, $\mathrm{df}=3 / 108, \quad p<.001$ ). Mean shock settings for each of the four blocks of trials, averaged over levels of anxiety and experience with pain, were, respectively, $1.92,2.35,2.89$, and 3.25 . The outcome of the previous trial (win-lose) also significantly influenced shock setting behavior $(F=14.5, \quad \mathrm{df}=1 / 36, \quad \mathrm{p}<.001)$. Ss were less aggressive following nonshocked trials (2.51) than shocked trials (2.70).

The interaction between the 


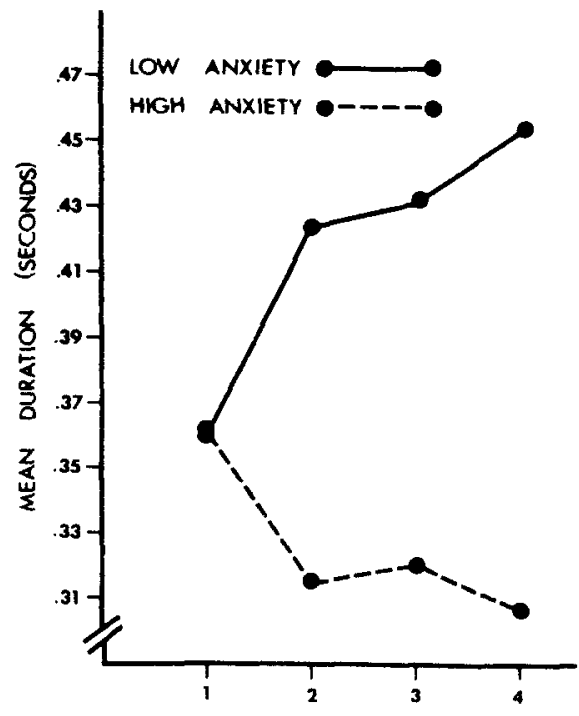

BLOCKS Of SIX TRIALS

Fig. 1. Mean shock durations as a function of anxiety and blocks.

provocation and previous outcome variables was significant at the .005 level $(\mathrm{F}=4.69, \mathrm{df}=3 / 108)$. Under low intensities of provocation, there was no apparent difference in shock settings as a function of the outcome of the previous trial. However, as provocation intensified, the difference in shock settings between the postwin and postlose trials increased.

The experience with pain manipulation interacted significantly with provocation and previous outcome ( $\mathrm{F}=2.72, \mathrm{df}=3 / 108$, $\mathrm{p}<.05$ ). This effect appears to be due to the fact that the Ss in the low-pain group increased their shock settings from the third to the fourth block of trials on both postwin and postlose trials. The Ss in the high-pain group, on the other hand, increased their shock settings only on postlose trials. On postwin trials, they continued to set the same intensity of shock that they had selected on the third block of trials.

While manifest anxiety did not influence the $\mathrm{Ss}^{\prime}$ actual shock selections, it did affect the intensity with which the Ss responded. As can be seen in Fig. 1, the low anxious Ss pressed the shock buttons for longer and longer periods of time. The high anxious Ss, on the other hand, pressed their buttons for shorter periods of time as a function of rising provocation. According to an analysis of variance performanced on mean duration scores, the Anxiety by Provocation interaction is significant at the .01 level $(\mathrm{F}=4.23, \mathrm{df}=3 / 108)$. DISCUSSION

Dengerink (1971) reported an inverse relationship between anxiety, as measured by Lykkens' APQ, and the expression of aggressive behavior. In this study, an attempt was made to replicate Dengerink's findings with the MAS, an accepted measure of "trait" anxiety. The attempt was unsuccessful; the Ss who scored low on the MAS were no more aggressive than the Ss who scored high on the MAS.

It is possible that the discrepancy between the results of the present study and Dengerink's is due to the inability of the MAS to assess fearfulness adequately. The results do not appear to support this position. As the intensity of the attack increased, the low anxious Ss pressed their shock buttons for longer and longer periods of time. This would appear to indicate that the low anxious Ss responded to the attack with increasing levels of anger. The high anxious Ss, on the other hand, pressed their shock buttons for shorter and shorter durations as a function of attack, suggesting that the high anxious Ss experienced heightened fearfulness as provocation increased. Thus, the results of this study support the contention that the Taylor Manifest Anxiety Scale assesses fear.

An item-by-item examination of the $A P Q$ suggests that the scale assesses more than a nonspecific predisposition to respond anxiously to a variety of situations. More specifically, a high score on the $A P Q$ appears to reflect one particular form of anxiety, i.e., social anxiety. It is possible that this situationally specific response tendency was responsible for the behavior evidenced by the $S s$ in Dengerink's study. There is independent, empirical support for the contention that social anxiety inhibits physical aggression. Taylor (1970) reported, for example, that high-need-for-approval Ss were less physically aggressive than low-need-for-approval Ss. Crowne \& Marlowe (1964) theorize that ". . . the approval-dependent person places high value on preserving his social acceptability ... [p. 164]." Taylor \& Epstein (1967) demonstrated that Ss who were provoked by female competitors evidenced high levels of physiological arousal and low intensities of counteraggression relative to Ss who were attacked by male competitors.

It has traditionally been assumed that a very close relationship exists between the expression of aggression and various underlying emotional states such as anger and fear. Presumably, the emotional concomitant of aggression is anger, while the emotional state corresponding to the inhibition of aggression is fear. The behavior of the low anxious $S$ corresponds rather closely to this traditional model; as attack increased, he appeared to respond in an increasingly angry manner. There appears to be a dissociation, however, between the emotional and behavioral tendencies of the high anxious Ss. While responding in an apparently fearful manner, as evidenced by decreasing buttonpress durations, the high anxious Ss increased the intensity of shock they wished to administer to their opponents. Thus, these results demonstrate that a person's underlying emotional state and overt aggressiveness can vary in an independent manner.

The Ss in this experiment evidenced a progressive tendency to set more intense shocks after losing than after winning. Similar findings were reported by Dengerink (1971). Since the intensity of shock continuously increased over blocks of trials, one could most parsimoniously interpret these results as being a manifestation of pain-elicited aggression (Ulrich, Hutchinson, \& Azrin, 1965).

\section{REFERENCES}

BANDURA, A. \& WALTERS, R Adolescent aggression. New York: Ronald Press, 1959.

BERKOWITZ, L. Aggression: A social psychological analysis. New York: McGraw-Hill, 1962.

CROWNE, D. \& MARLOWE, D. The approval motive. New York: Wiley, 1964. DENGERINK, H. Anxiety, aggression, and physiological arousal. Journal of Experimental Research in Personality, $1971,5,223-232$.

LYKKEN, D. A study of anxiety in the sociopathic personality. Journal of Abnormal \& Social Psychology, 1957, 55, 6-10.

TAYLOR, S. Aggressive behavior as a function of approval motivation and physical attack. Psychonomic Science, $1970,18,195-196$.

TAYLOR, S., \& EPSTEIN, S. Aggression as a function of the interaction of the sex of the aggressor and the sex of the victim. Journal of Personality, 1967, 34, 474-486.

ULRICH, R., HUTCHINSON, R., \& AZRIN, $\quad$ N. Pain-elicited aggression. Psychological Record, 1965, 15, 111-126. 